\title{
A model of computer support to mobile learning in the Senegalese educational system
}

\author{
Marie Hélène Wassa \\ Mbalo \\ PhD student \\ Cheikh Anta Diop \\ University \\ Dakar,Senegal \\ Mballomaria@yahoo.fr
}

\author{
Alassane Diop \\ Teacher-researcher \\ Alioune Diop University \\ Bambey,Senegal \\ Alassane.diop@uadb.edu.sn
}

\author{
Richard Hotte \\ Researcher \\ Research center LICEF- \\ TELUQ \\ Montreal,Canada \\ Richard.hotte@teluq.ca
}

\author{
Ibrahima Niang \\ Teacher-researcher \\ Cheikh Anta Diop \\ University \\ Dakar,Senegal \\ Ibrahima niang@hotmail.co
}

\begin{abstract}
This article aims to present a model for mobile learning. The model is using a decentralized system with delocalized subsystems. The solution is based on the use of mobile technology and online labs. It also fits the needs of distance learning institutions (DLIs) and the virtual university recently established in Senegal. This model of learning tool mainly targets professionals on the move within the country (Senegal) or abroad. These professionals, lacking the time for in situ training, are thus given the opportunity to take courses via a learning platform using mobile devices and facilities (cell phones and tablets). Our main challenge is to provide quality service by ensuring connection and permanent availability. Senegal is the setting of the study. This article especially focuses on the technological innovations adopted. The latter are based on a detailed study and analysis (functioning, algorithm) of learners' mobility. These technologies aim to ensure, among other things, the quality and performance of the interactions that are at the foundation of the collaboration.
\end{abstract}

Keywords—mobile technology; mobile learning; ODS;routing geographic

\section{INTRODUCTION}

Online learning is fast evolving and, presently, mobile learning is the current reality which fits the needs of ever moving learners. Mobile learning is learning supported by a mobile device and wireless technologies. It aims to help people on the move to have access to training without them having to resort to heavy equipment. Despite significant advance in mobile learning, its application is not so widespread in distant teaching.

Indeed, this type of learning does not fit learners' needs in terms of formal teaching. There is definitely some gap to fill. Mobile learning is facing quite a lot of challenges, both in educational and technological terms. So, in order to make mobile learning more formal, the approach proposed in this article combines the distance learning model and the use of mobile devices and online labs (tele labs) while ensuring perfect collaboration among learners. This approach will help the Virtual University of Senegal which was recently established for the benefit of learners and distance learning institutions of traditional universities. This article will deal, first, with current studies, and, second, with the solution proposed.

\section{CURRENT STUDIES ON MOBILE LEARNING}

Mobile devices are gaining ground throughout the world. Several studies (worldwide, two of the most successful mobile learning models currently used in schools are the "' a student a device" type of programs (1: 1), whereby each student is provided with a device, free of charge; .....Excerpt from [1] deals with mobile learning. Thus the latter is integrated in formal learning through introducing mobile devices for improving in situ courses [1]. Several universities worldwide integrate mobile learning in their training offer [2] [3] [4]. This type of learning may be either in situ or distance learning.

The advent of online laboratories allows the handling of equipment, facilities as well as online and remote systems without the user having to go to a particular physical place. Remote labs may be regarded as teaching aids. Indeed, they provide the learner with more flexibility and autonomy in their search for training processes. The integration of mobile learning will definitely improve this learning system.

Mobile learning as a training model fits the needs of the learners who are facing spatiotemporal constraints. Indeed, it ensures improved autonomous learning. Another feature of mobile learning is its potential for guaranteeing collaboration between various distant learners for a better understanding of pedagogic resources.

So, for an improved valorization of mobile learning's benefits, M. Ahmed Nacer show how the advance of mobile technology has led to the development of applications for collaborative editions [5]. The development of this aspect made us integrate collaborative learning inside mobile learning.

Collaborative learning, according to S. George [6] requires from learners, responsibility and social skills. Indeed, learners are responsible for their owning learning as well as that of the others. 
The learner is given full liberty in the collaborative learning approach. The activities are not fully directed and learners are mostly responsible for their group work. For example, in collaborative learning, the teacher does not assign the learners' roles ; they are the ones that negotiate their own roles among them.

This type of learning may be computer supported to fit the needs of online teaching, hence the name of Computer Supported Collaborative Learning (CSCL). CSCL is a learning approach that combines collaborative learning with information and communication technologies. Online teaching, generally individual, will be more interactive in CSCL [6]. Indeed, communication will not be only between the learner and the teacher, but among learners as well.

With the proliferation of mobile devices (smartphones, tablets......) and the advance in mobile technology, there is an opportunity for collaborative online teaching to use these mobile facilities as teaching aids, hence the notion of mobile learning. This has led to the definition of the current concept of Mobile Computer Supported Collaborative Learning [7].

MCSCL is very advantageous for learners who are permanently on the move for professional reasons. Indeed, it presents a strong potential for supporting collaboration and interaction among learners, larger learning autonomy for the learner who is given the opportunity to be in touch with other learners as well as with the coach or tutor anytime and anywhere.

However, the use of mobile facilities as teaching aids has a number of drawbacks, despite the proliferation of devices socalled smart because of the wide range of services they offer the users (communication, information, learning......). Indeed, limited memory, limited processing capacity, short battery life,and... are some constraints for quality teaching. So, one has to take these constraints into account if one has to propose a viable mobile learning [8].

To address the constraints of mobile facilities, several studies are being conducted on technological infrastructure by using either calculation grids or Cloud Computing [9] [10] [11] [12] [13] [14] [15] [16]. These two technological infrastructures will instill processing power to mobile facilities in the learning process. The approach will improve the processing capacity, thus allowing for the integration of remote labs.

So, to make sure our system is apt for offering a better potential for collaboration, we propose a solution oriented to learners' localization. To this end, we define a position and routing protocol based on learner's geographic position.

\section{SOLUTION PROPOSED}

Our contribution is part of a process for establishing a mobile system whose aim is to improve the training capacity of distance learning institutions (DLIs) as well as the VUS [17] [18]. VUS is a digital university essentially based on technological infrastructures and computer networks. So, VUS is present wherever the Internet is available. VUS is backed by a network of twelve open digital spaces (ODS) which make VUS a local university. ODSs are distributed throughout the Senegalese territory. The other Senegalese universities integrate DLIs in their training offer.

So, to fit the needs of these universities, we are proposing a mobile learning system which combines mobile technologies and remote labs for online training. As indicated above, this learning system targets professionals that have to move around

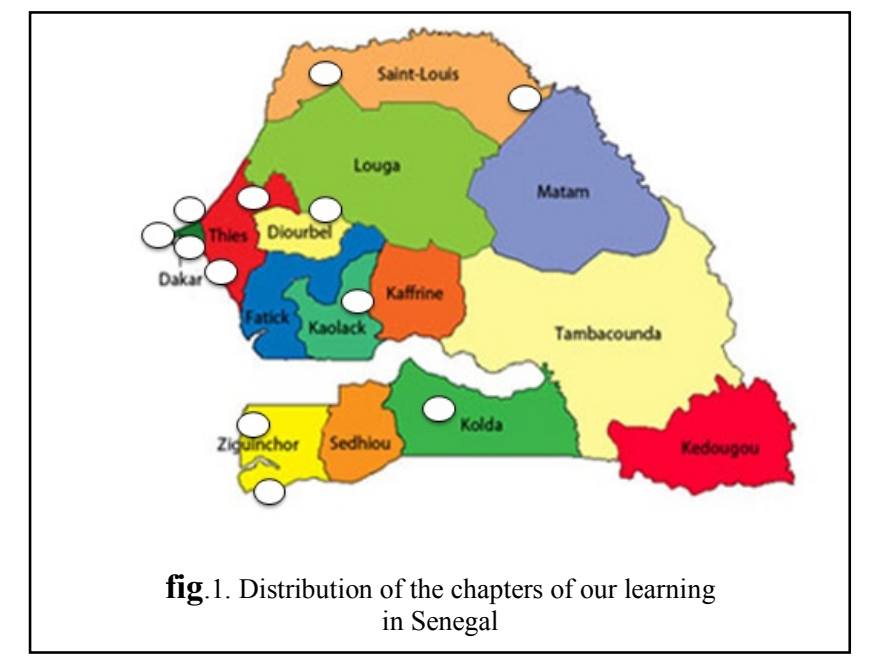

the country (Senegal) for professional reasons. Access to the course is made possible by the use of mobile devices such as tablets and smartphones wherever the learner is located.

Our model is based on a centralized system with subdecentralized systems. The latter are cells installed throughout Senegal, matching the location of various online training institutions. Each cell is provided with an Open Digital Space (ODS). Learners and resources (human and material) are associated with each ODS.

\section{2) Cells'functioning}

In our solution, we install a learning management system in each ODS (mobility algorithm). The management of mobile learners is done according to their situation via an intermediate server (IS) responsible for the area. The server maintains a database from the central server containing a certified true and up to date copy of the learner's profile. To situate the learner, the system will use GPS technology (Global Positioning System). All intermediate servers are connected to the central server (CS) which is included in a Cloud Computing system.

\section{A. Description of solution}

\section{1) Presentation}


The ISs download the various learners' request from the central server, thus helping to avoid its clogging -of central server- as well as its unavailability. The SI provides the following services .

- Registration

- Updating

- Identification

- Localization

- Connection

- $\quad$ Service search

- Collaboration

- Access to course and resources

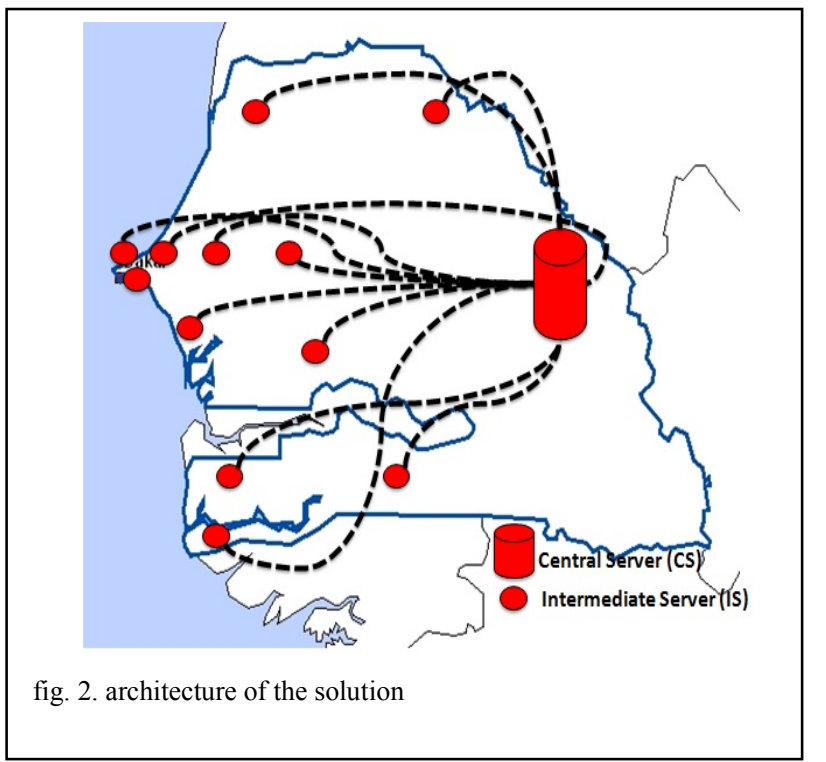

Fig. 3 shows the physical architecture of a cell, composed of learners with their mobile facility and intermediate server which coordinates tasks. The main task of the learner is to register at the ODS of his/her cell.

Registration is made automatically without the learner's intervention. The algorithm uses the GPS in the learner's device to locate the latter. All these actions are performed in the background and in a transparent way.

The learner's profile is already included in the central server as of the first registration. During this registration, a default ODS (the nearest ODS) is allotted to the learner by his/her institution or university. The learner is directly connected to the home interface of the learning platform; he/she shows his/her National Student Identity (NSI) and password for connection. The learner has then access to the intermediate server. Prior to authorizing access to the IS, the CS transmits all the learners' details (profile) to the IS. Once all these steps are made, the learner is registered in the IS.

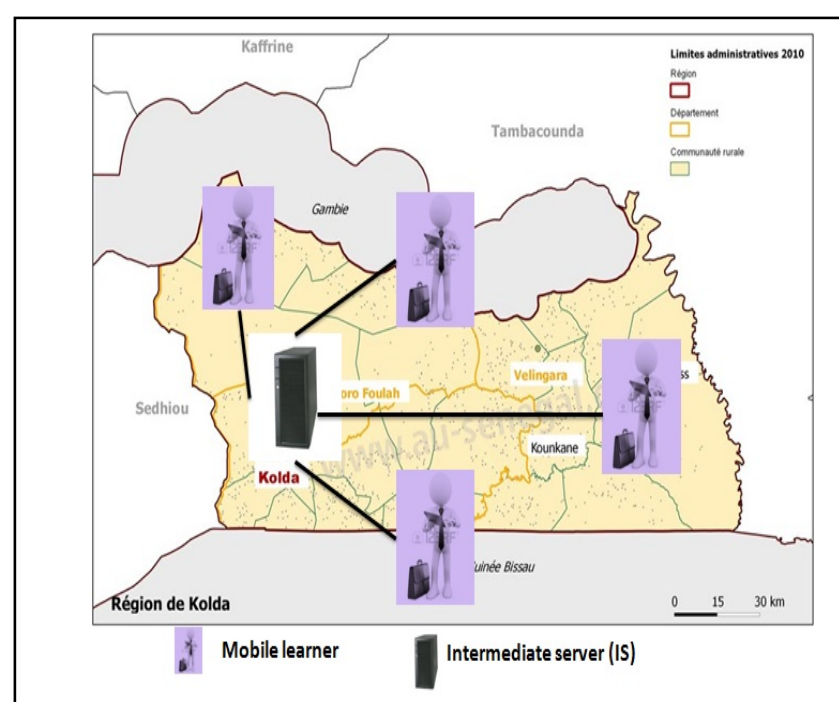

fig. 3. physical architecture of a chapter

Once the user is connected to the learning system, they can view all other learners connected to the same cell. So, they can have access to all authorized courses and resources. Collaboration among learners may be made through messages, video calls and through contributions to an online course.

When a learner wishes to be transferred to another cell, an updating and information transfer is automatically launched between cells (between ISs).

Fig. 4 shows the architecture of the IS software which is composed of three layers, the user interface and the storage facility.

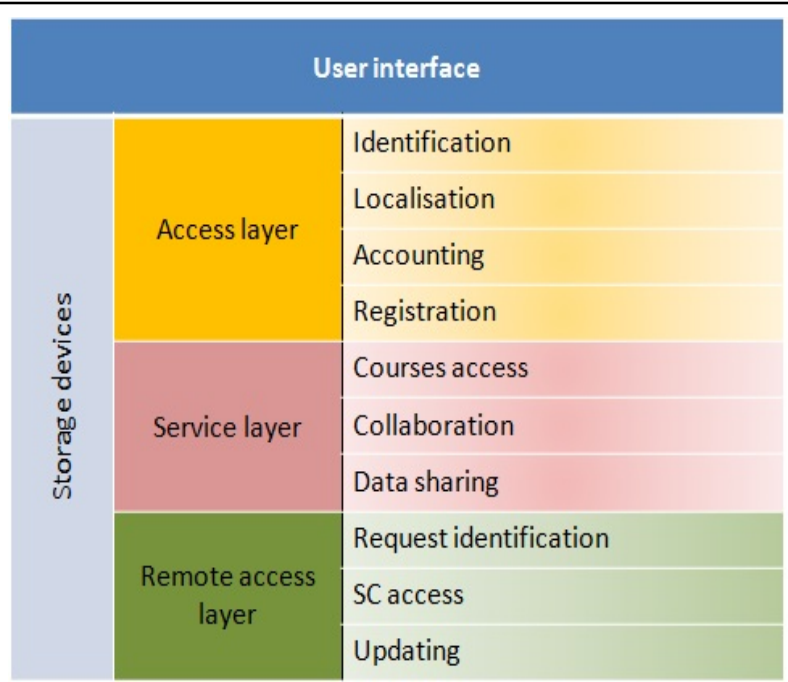

fig. 4. IS Architecture

- User interface:it is a graphic interface dedicated to users of the learning system. Users may be learners, coaches, tutors, counselors;

- Storage facilities: physical support that helps to store the system's various datasets;

- Access layer: it is the set of services to users. These services rage from access to course contents (texts, images, videos), to collaboration among users and resource sharing. 
- $\quad$ Remote access layer: enables users to connect to a remote server in case one task has to be performed at the level of a remote lab. To that purpose, the intermediate server before connection to the central server first check the user's request.

\section{3) Functioning of central server (CS)}

The central server (CS) provides the following services:

- Registration

- Updating

- Identification

- Access to remote lab

- Request processing

- Addition and updating of courses

- Learning management

All the ISs are connected to the central server (CS) which is included in the Cloud Computing The CS processes all data sent to the remote lab. It centralizes details about learners and courses available.

Fig. 5 shows the architecture of the CS included in the Cloud Computing. This server is subdivided into several servers as follows:

- Access server: ensure access to Cloud Computing to various users of the mobile learning system;

- Application server:enables access to various services and applications available to users;

- Calculation server: comes I varying numbers and helps to process data sent to the remote lab. The presence of numerous calculation servers will help to avoid clogging;

As regards the software architecture of our $\mathrm{CS}$, it is composed of three software layers, storage devices and the access interface of the ISs.

- IS interface : it is a graphic interface devoted to the various ISs present in the cells;

- Storage devices: physical support that helps to store the system's various data;

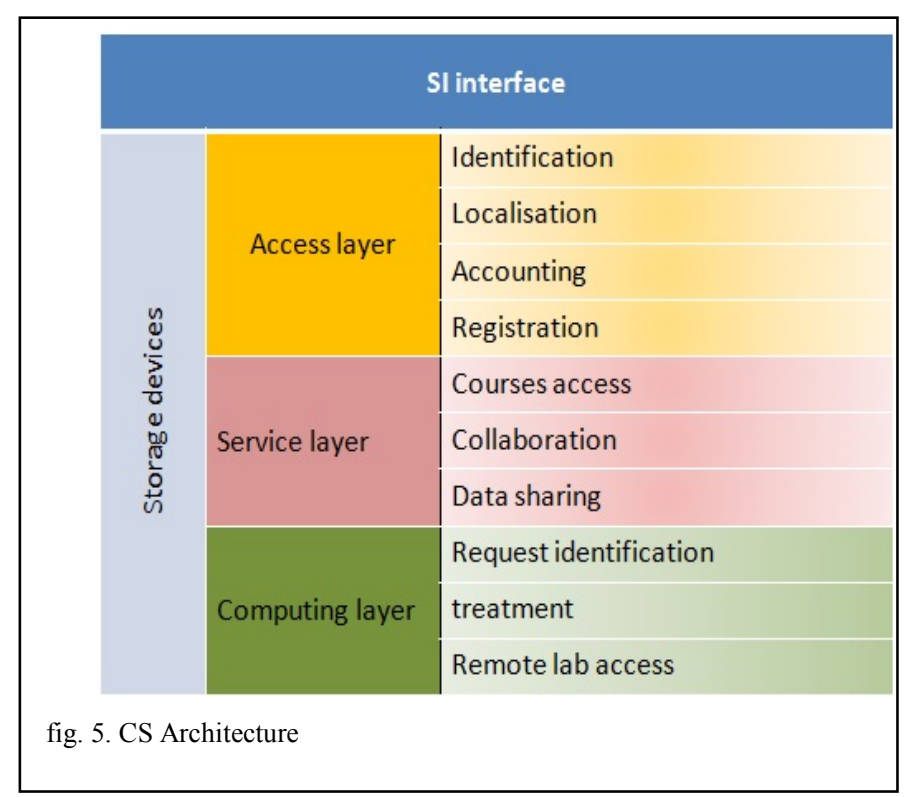

- Access layer: it is the set of services that control users access, namely their identification, localization, traceability, registration and updating;

- Service layer: it is the set of services available to users. These services range from access to course contents (texts, images, videos), to collaboration among users and resource sharing;

- Remote Access layer: Checks users' requests then routes them to the remote lab which allows distant handling.

\section{B. Functioning of position and routing algorithm}

Among other things, our work aims to propose an efficient mobile learning system that will enable users to access and use remote labs. Mobile learning necessarily implies constraints relating to mobile devices (limited processing and storage capacity, low battery...). To address those constraints, we propose to use a geographic positioning and routing approach in the learning system that is yet to be installed.

Our system puts together all distance learning institutions in the high educational system in Senegal. That includes the VUS and Distance Learning Institutions in the other traditional universities.

The following entities are present in each institution:

- The learner: which provides the details about the learners including the following fields (national identification number, first and last names, the department and region of the institute)

- Institute: provides information about high educational institutions with the following details (name of the institute, the department and region where the institute is located)

- ODS: provides details regarding open digital spaces present in the institutions which may accommodate several ODSs. The following information is available (ODS geographic details, name of the ODS)

- Lab: provides information on the labs connected to the ODSs, with the following information (lab's center of interest, its geographic details)

- Material: provides information regarding the material existing in the labs with the following information (description of material)

- $\quad$ Training personal : provides information about the training personal (teachers, tutors) active in the ODS with the following information (first and last names, date of birth and teacher's specialty)

Each institution accommodates one or several ODSs distributed in various areas. Each ODS has a number of students according to the intervention area. Each learner may connect to the ODS of their choice within a 
given institution. Considering the VUS, which is our area of research, it is composed of 12 ODSs distributed throughout the country as shown in the following figure:

The network is subdivided into several subnetworks according to the ODS location. For an improved localization of mobile learners, and also to associate them with an ODS according to their situation or to the availability of an ODS, we will use a routing protocol based on the geographic situation. As indicated in fig. 8 above, every ODS covers a set area with a number of mobile learners.

Our learning system is based on the following algorithms

- Learning registration in an institution and their placement in their ODS

- Learner localization

- Data routing

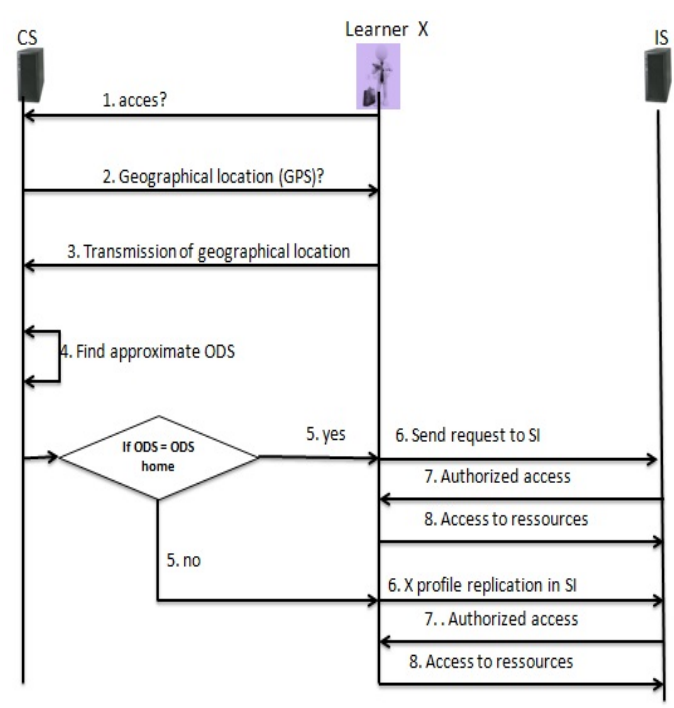

fig. 6. Procedure of localization and registration

\section{1) Learner registration}

Registration of the learner consists in placing them in an ODS which will be their home and will store the following details:

- User name

- Last name

- First name

- Date of birth

- Place of birth

\section{2) Learner localization and positioning}

Learner localization learner is made upon the institute's URL call. The learner's request is routed to the nearest ODS according to their geographic position. The ODS server records the geographic position of the learner. Frequent updating regarding their position is sent to the server:

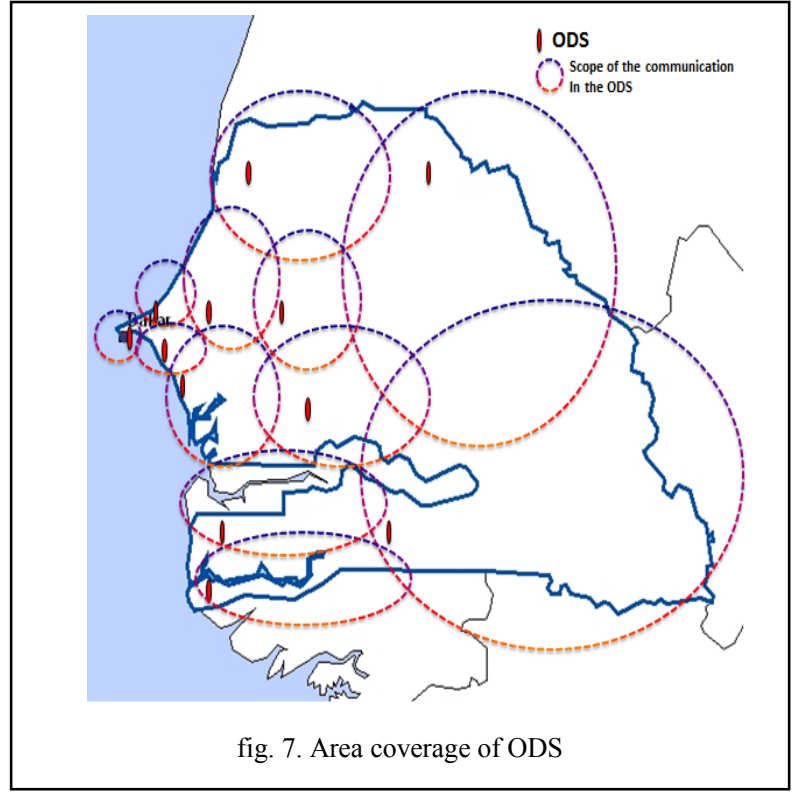

The different steps of the algorithm for learner localization are as follows:

Step1. URL call from the distant learning institute

Step2. Retrieval of geographic position of mobile learner through getCurrentPosition() method.

Step3. Searching nearest ODS according to its geographic position and load (number of maximum learners supported by the connection. This information will be provided by the compare() method, taking into account learner's geographic parameters as well as the table of various ODSs geographic parameters.

Step4. Redirecting request to nearest ODS through the request performed in previous step.

Step5. : Upon mobile learner's connection via his/her password, two cases may occur:

- Case 1: If current ODS is different from mobile learner's default ODS, then all learner's detail will be copied from default ODS and put into the current ODS. After that, the mobile learner will be authorized to connect.

- Case 2: If current ODS matches learner's default ODS, then learn may connect.

For this 5th step, the rechercheENOdom () method, taking as parameter the username and the password of the mobile learner, helps to search the home ODS.

Step 6: Once the connection is established, frequent updating is required, regarding the geographic position of the mobile learner, through the miseajourfrek () method, taking learner's username as parameter.

\section{3) Routing information}

Once localization and positioning are performed, routing will be implemented at two levels: 
- Intra ODS : it is about routing the data among the learners of the same ODS through the base ODS.

- Inter ODS: It is equally implemented by the ODSs within each ODS.

\section{4) Perspectives}

for optimum use of our algorithm, the following parameters must be taken into consideration:

a) Deletion of the data of an $O D S$

- Is this done upon learner's disconnection?

- Is this done after laps of time following disconnection?

\section{b) Choosing current $O D S$}

- Considering the ODS load as well as its nearness

\section{c) Learners collaboration}

\section{CONCLUSION}

In this article, we have proposed a computer based mobile learning system with mobile devices. This solution is part of an effort to consolidate distance learning in the Senegalese educational system .

This model is composed of cells distributed throughout Senegal. These cells accommodate an Open Digital Space where the learner can connect and have access to various services available. In the article, we focused on the various components of our model, the functioning algorithms, and the software's architecture. In the future we are aiming to deploy this computer model and conduct a performance study with a focus on service quality.

\section{REFERENCES}

[1] Unesco, "l'avenir de l'apprentissage mobile :implications pour la planification et la formulation de politiques," Paris, 2013.

[2] Sharples, "The Design of Personal Mobile Technologies for Lifelong," Computer and Education, pp. 177-193, 2000.

[3] Sharples, Corlett et Westmancott, "The Design and Implementation of a Mobile Learning Resource,'Personal and Ubiquitous Computing, pp. 220-234, 2002.
[4] M. Ally et A. Palalas, "State of Mobile Learning in Canada and Future Directions,"'Canada, 2011.

[5] M. Ahmed-Nacer, P. Urso, C. L. Ignat et G. Oster, "Evaluation de l'occupation mémoire des CRDTs pour l'édition collaborative tempsréem mobile," UbiMob-French-speaking conference on Mobility and Ubiquity Computing, 2012, 2013.

[6] S. George, "Apprentissage collectif à distance. SPLACH: un environnement informatique support d'une pédagogie de projet,"' Maine, 2001.

[7] S. Caballé, F. Xhafa et L. Barolli, "Using mobile devices to support online collaborative learning".

[8] H. T. Dinh, C. Lee, D. Niyato et P. Wang, "A survey of Mobile Cloud Computing:Architecture, Applications, and Approaches," Wireless Communications and Mobile Computing, 2013.

[9] H. Dinh, C. Lee, D. Niyato et P. Wang, "A Survey of Mobile Cloud Computing:Architecture, Applications , and Approaches," Wireless Communication and Mobile Computing, 2013.

[10] X. Chen, J. Liu, J. Han et H. Xu, "Primary Exploration of Mobile Learining Mode under a Cloud Computing Environment," International conference on E-Health Networking, Digital Ecosystems and Technologies (EDT), 2010.

[11] H. Gao et Y. Zhai, "System Design of Cloud Computing Based on Mobile Learning," 3rd International Symposium on Knowledge Acquisition and Modeling (KAM), 2010.

[12] J. Li, "Study on the Development of Mobile Learning Promoted by Cloud Computing," 2nd International Conference on Information Engineering and Computer Science (ICIECS), 2010.

[13] W. Zhao, Y. Sun et L. Dai, "Improving computer basis teaching through mobile communication and cloud computing technology," in 3rd International Conference on Advanced Computer Theory and Engineering (ICACTE), 2010.

[14] C. Yin, B. David et R. Chalon, "Use your mobile computing devices to learn - Contextual mobile learning system design and case studies," in 2nd IEEE International Conference on Computer Science and Information Technology (ICCSIT), 2009.

[15] R. Rieger et G. Gay, "Using mobile computing to enhance field study," in 2nd international conference on Computer support for collaborative learning (CSCL), 1997.

[16] R. Ferzli et I. Khalife, "Mobile cloud computing educational tool for image/video processing algorithms," in Digital Signal Processing Workshop and IEEE Signal Processing Education Workshop (DSP/SPE), 2011.

[17] M. H. W. Mballo, R. Hotte, A. Diop et I. Niang, "Mobile learning, a solution to vocational training in Senegal," in International Conference on Web \& Open Access to Learning, Dubai (United Arab Emirates), 2014.

[18] UVS, "UVS," 2014. [on line]. Available: http://www.uvs.sn/. [access at 06 Novembre 2014].

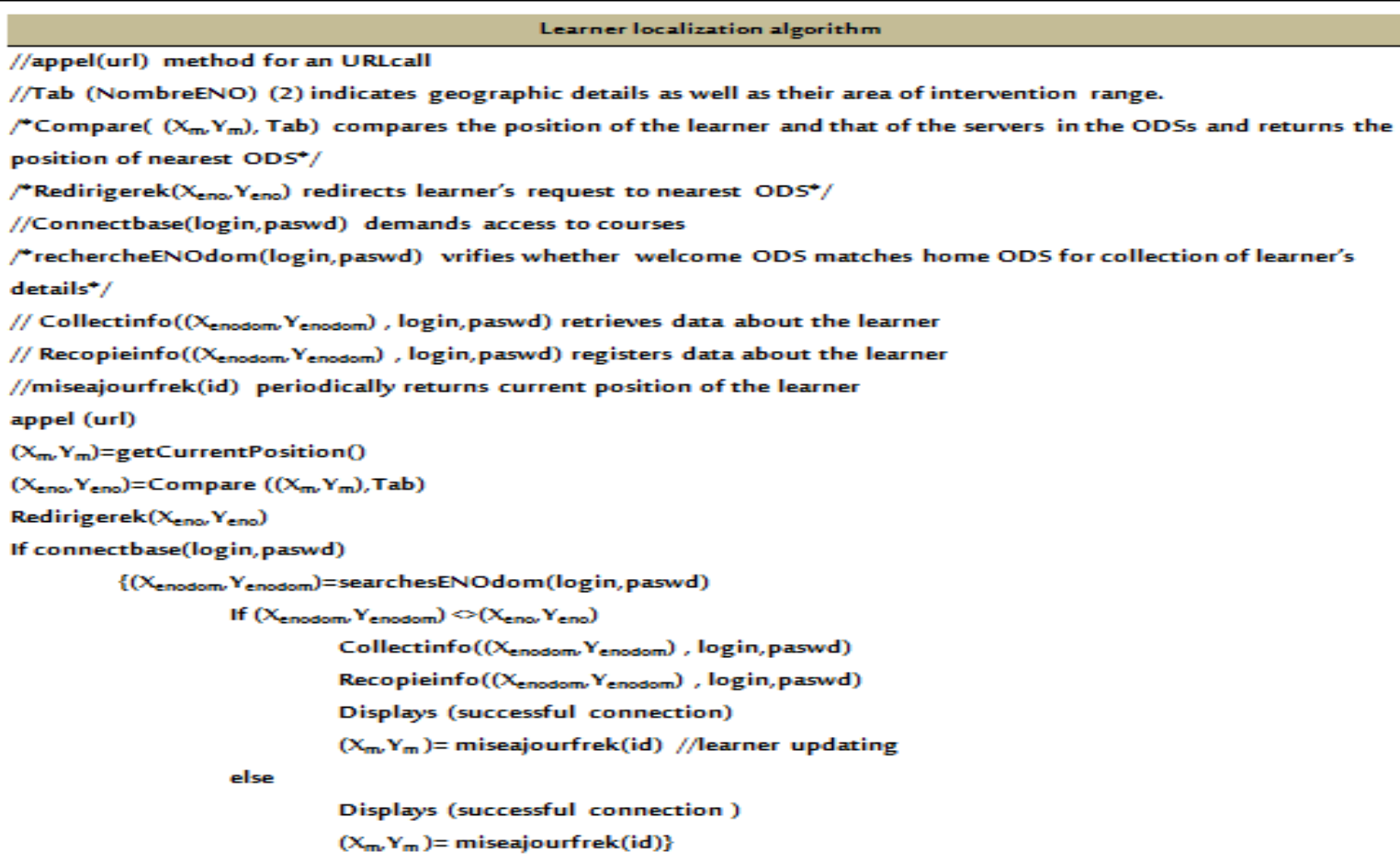

